\title{
The Brain Topology of Fast Ripples, and their Correlation with Epilepsy
}

\section{Carla García-Barba and Laura Medina-Ceja ${ }^{*}$ \\ Laboratory of Neurophysiology and Neurochemistry, Department of Cellular and Molecular Biology, CUCBA, University of Guadalajara, Jalisco, México}

*Corresponding author: Laura Medina-Ceja, Laboratorio de Neurofisiología y Neuroquímica, Departamento de Biología Celular y Molecular, Centro Universitario de Ciencias Biológicas y Agropecuarias, Universidad de Guadalajara, Camino Ing. R. Padilla Sánchez 2100, Las Agujas, Nextipac, Zapopan, Jalisco, México, CP 45110. Tel: + 523337771191 ext. 33201; Fax: + 5233 37771191; E-mail: lmedina@cucba.udg.mx

Rec date: Mar 27, 2014, Acc date: May 27, 2014, Pub date: Jun 01, 2014

Copyright: (C) 2014 Barba CG, et al. This is an open-access article distributed under the terms of the Creative Commons Attribution License, which permits unrestricted use, distribution, and reproduction in any medium, provided the original author and source are credited.

\begin{abstract}
High frequency oscillations (ripples $80-250 \mathrm{~Hz}$ and fast ripples $250-600 \mathrm{~Hz}$ ) have been widely studied in the last decade for their potential role as a more precise biomarker of the seizure onset zone, in particular fast ripples. The hippocampus is the best described brain topology as well as its association with this activity. However, in recent years; several groups have analyzed the association of high frequency activity with extra-temporal epilepsies, which could eventually influence the decision making process in the pre-surgical evaluation ensuring a better outcome in patients suffering from different forms of intractable epilepsy. In this review, the brain topology of fast ripples and several human pre-surgical studies were analyzed using fast ripple activity as an epileptogenic biomarker, also it was reviewed the preferred methods of recording for detecting high frequency oscillations in every case.
\end{abstract}

Keywords: Fast ripples; High frequency oscillations; Hippocampus; Neocortex; Ripples; Seizure onset zone; Temporal lobe epilepsy

\section{Abbreviations: \\ AEDs: Antiepileptic Drug; EPSP: Excitatory Postsynaptic Potentials; Glu: Glutamate; HFO: High Frequency Oscillations; FR: Fast Ripples; HS: Hippocampal Sclerosis; IPSP: Inhibitory Postsynaptic Potentials; MRI: Magnetic Resonance Imaging; SOZ: Seizure Onset Zone; SWS: Slow-Wave Sleep; TLE: Temporal Lobe Epilepsy}

\section{Introduction}

Epilepsy is a worldwide health problem. According to the World Health Organization, 50 million people were estimated to suffer from this disease in 2012, and nearly $80 \%$ of this population is concentrated in developing countries. Given a proper treatment, epilepsy responds in $70 \%$ of the cases. However, due to the health conditions in developing countries, this percentage drops drastically.

The epileptic seizures have a broad spectrum of clinical symptoms that depending on the type of epilepsy and their cause they are associated with different degrees of cognitive impairment and response to treatment. At cellular level, seizures are caused by the continuous and hyper-synchronized firing of a group of brain neurons $[1,2]$ which generates specific patterns in the EEG. Likewise, this hypersynchronized firing is the result of the unbalance between excitatory and inhibitory activity, caused by the increased effect of the neurotransmitter Glutamate (Glu) as well as the decrease of the GABA neurotransmitter [2-4].

One of the challenge that remain for both the clinical medicine and experimental studies is the accurate localization of the epileptogenic zone, in order to predict, diagnose and treat this disease more efficiently. This problem has led to the search of a precise biomarker for epilepsy, especially the kind that responds poorly to antiepileptic drugs (AEDs) and is associated with bad prognosis (since it can even culminate on sudden unexpected death in epilepsy or SUDEP) and refractory seizures. This entity is also known as pharmaco-resistant epilepsy [5].

There are some predictors of pharmaco-resistance, such as the cause of the epilepsy (symptomatic epilepsy, for instance is more likely to respond less to AEDs, than idiopathic) [6], the age of onset, being more dangerous those that present at the neonatal stage and after 12 years-old [7], the presence of physical abnormalities and mental disabilities among other signs [8].

One of the most pharmaco-resistant epilepsies is temporal lobe epilepsy (TLE), which is associated with magnetic resonance imaging (MRI) abnormalities (hippocampal sclerosis) and poor response to AEDs. This sort of epilepsy often leads to surgery, and even after surgery one third of the patients will continue having seizures [9].

The analysis of the pathological networks formed in TLE notices high synchrony as one important element in the ictal event $[10,11]$. However, interictal activity, such as spikes, holds relevance, as they can participate in the development of comorbities, mostly causing impairment in cognitive processes [12].

In this context, the need of a precise biomarker arose. Several study groups have presented evidence of high frequency oscillations (HFO); in particular fast ripples (FR, 250-600 Hz) as a possible response to this need $[1,13]$.

\section{High Frequency oscillations related to epilepsy}

This phenomenon is described as an oscillatory field potential that reflects short term synchronization of neuronal electrical activity, ranging from 80 to $600 \mathrm{~Hz}$ [14]. Gamma activity $(30-80 \mathrm{~Hz})$ will not be considered in this review, since is related to physiological activity [15], and whereas ripples $(80-250 \mathrm{~Hz})$ and particularly fast ripples (250-600 $\mathrm{Hz}$ ) are often correlated with epileptogenic phenomena [14]. 


\section{Ripples}

Ripples are oscillations ranging from 80 to $250 \mathrm{~Hz}$, which are found in the normal rat and human hippocampus and enthorrinal cortex, except in the dentate gyrus [16], where they are associated to epileptic processes. This activity has been associated in the process of long term potentiation trough the communication of the hippocampus with extra hippocampal structures; there is evidence that this event occurs particularly in the Slow-Wave Sleep (SWS) [17].

This activity is generated by the "concert" of the intrinsic cellular activity and the coordination of a group of neurons. The intrinsic cellular activity is translated as inward currents of $\mathrm{Na}^{+}$and $\mathrm{Ca}^{2+}$, and outward currents of $\mathrm{K}^{+}$that cause slow after hyperpolarization [18]. The coordination of cellular groups has been hypothesized to happen in very different mechanisms: The generation of ripples is related to the presence of inhibitory postsynaptic potentials (IPSP) created by interneurons, each one of them affects the action potential generation of several neurons in the pyramidal layer of the CA1 region of the hippocampus $[19,20]$. However this mechanism is associated with memory formation.

\section{Fast ripples}

FR reflect bursts of population spikes from synchronously firing principal cells in relatively small areas $\left(1 \mathrm{~mm}^{3}\right)$ [21,22], these containing several pathologically interconnected neuronal clusters [1]. Their spectral range lies between $250-600 \mathrm{~Hz}$, and can last from 10 to $60 \mathrm{~ms}$ (Figure 1). They are mostly found in dentate gyrus, CA1/CA3, subiculum and entorhinal cortex [23] and, like ripples, are elicited during SWS. FR activity occur in the same hemisphere in relation to the lesion, both in humans with TLE and rats treated with KA [14], in a total volume of brain tissue of $1 \mathrm{~mm}^{3}$, however this area can increase in the absence of inhibitory activity $[21,22]$.

Some mechanisms related to generation of fast ripples are: The formation of aberrant synapses between pyramidal cells in the epileptic process, resulting in the generation of excitatory postsynaptic potentials (EPSP) that synchronizes hippocampal neurons [24], causing seizures. It has been also analyzed the potential role of gap junctions, where the affected neurons depolarize adjacent neurons through axonal coupling [25]. Another proposed hypothesis is the participation of ephaptic interactions, in this model; the electric field generated in the extracellular field is strong enough to depolarize adjacent neurons, thus triggering an action potential [26]. Finally, the generation of a field potential created by a group of synchronized neurons can recruit neurons nearby, increasing the field power and causing this kind of activity [26].

The fundamental difference between ripples and FR (Table 1), is the value as a biomarker that holds the later, since they can only be found in the eventually epileptic brain [14]. And it also correlates with the severity of the disease since there are more FR in the presence of more seizures [27]. In this respect, several examples of association between the appearance of HFO in the resection zone and surgical outcome in patients have been reported. Ochi and coworkers [28] studied retrospective data of 9 children who underwent intraoperative subdural EEG, 4 of them had seizure freedom.

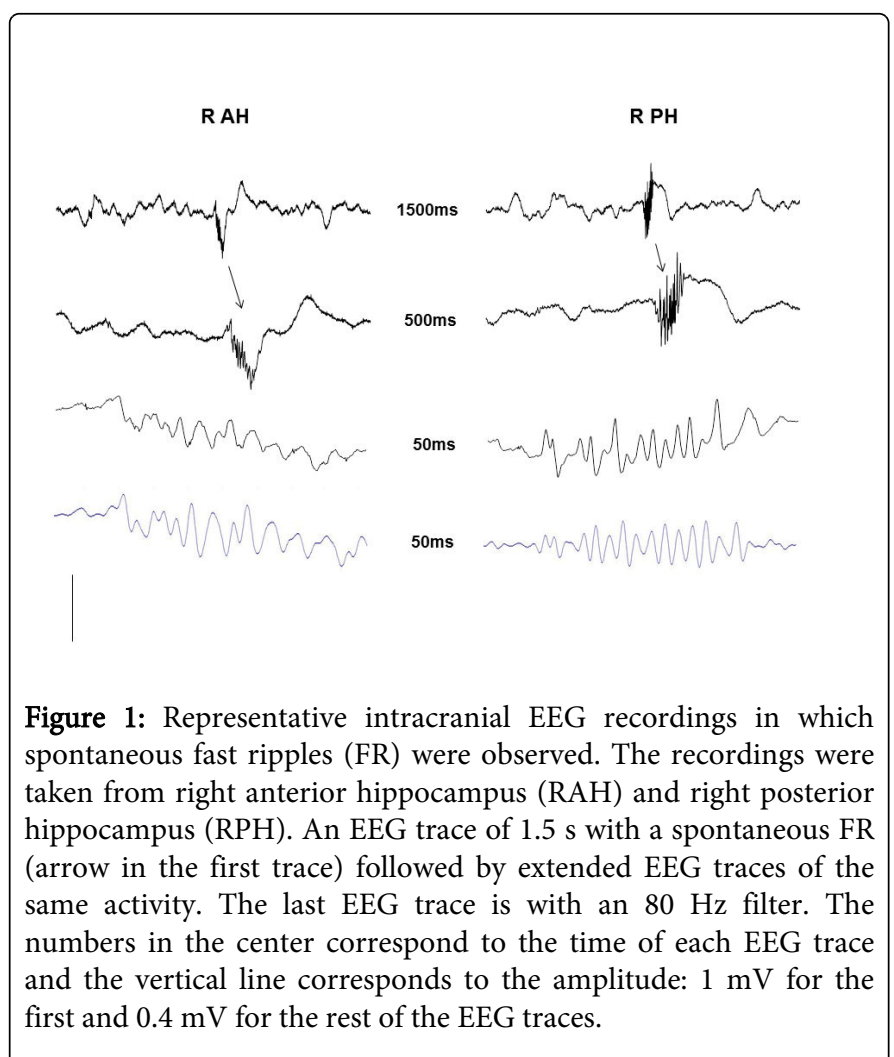

In comparison to the residual seizure group, the seizure free group showed more frequency of HFO within the resection zone $(\mathrm{p}<0.001)$ after the clinical onset of the seizures. In the same way, the group of Akiyama [29] studied 28 pediatric patients with history of intractable epilepsy. They found through the intracranial video EEG (VEEG) of patients a significant relation between the $\mathrm{FR}$ resection ratio $(\mathrm{p}=0.046)$ and seizure outcome within a 2 years post-surgical period. They also found that the 18 patients scheduled for multiple lobe resections had a larger FR size than those with single lobe involvement. Regarding ripples, they only found improvement of seizures when resected the region in which they were contained but not seizure freedom. In other study [30] were analyzed retrospectively the intracranial EEG recordings performed in 44 pediatric patients with intractable epilepsy in both temporal and extra-temporal regions. It was found 41 patients with HFO (ripples and FR). From 22 patients with the HFO region resected, 18 had a seizure free outcome, whereas only $21 \%$ of patients achieved seizure freedom with incomplete HFO region resection.

\begin{tabular}{|l|l|l|}
\hline HFO & Ripples & Fast Ripples \\
\hline Spectral frequency & $80-250 \mathrm{~Hz}$ & $250-600 \mathrm{~Hz}$ \\
\hline Location & $\begin{array}{l}\text { Hippocampal formation (mostly in CA1and entorhinal } \\
\text { cortex), physiological ripples can be found in } \\
\text { neocortex as well. }\end{array}$ \\
\hline
\end{tabular}


Citation: Barba CG, Ceja LM (2014) The Brain Topology of Fast Ripples, and their Correlation with Epilepsy. J Neurol Disord 2: 162. doi: $10.4172 / 2329-6895.1000162$

Page 3 of 5

\begin{tabular}{|l|l|l|}
\hline Duration & $30-160 \mathrm{~ms}$ & $10-65 \mathrm{~ms}$ \\
\hline Rate per minute & $0.1-60 / \mathrm{min}$ & $0.5-6 / \mathrm{min}$ \\
\hline Physiological activity & Memory formation & Evoked somatosensorial response \\
\hline
\end{tabular}

Table 1: Comparison of high frequency oscillations (HFO) associated to epileptogenesis.

The presence of ripple or FR activity in the dentate gyrus can be linked to early appearance of spontaneous seizures [31]. Recent studies have proven that is important not only to distinguish the width band of the activity, but its pattern, since FR occurring in a discontinuous manner tend to be more closely related to the seizure onset zone (SOZ), than continuous FR with high frequency activity in the background [32].

\section{Brain Topology of Fast Ripples}

\section{Temporal lobe epilepsy}

It has been well described the characteristics of FR in TLE, both in animals (particularly in rats) and humans. In animal models of TLE, FR are observed in dentate gyrus, in CA1/CA3, subiculum and entorhinal cortex [23]. Two important elements in the interpretation of high frequency activity are the time of onset of HFO, which correlates strongly with the time of onset of spontaneous seizures and topology, even within the hippocampal formation, ripple frequency detected in dentate gyrus strongly correlates with an ongoing pathological process as well as FR. Animals with HFO detected earlier in dentate gyrus, presented spontaneous seizures before other animals [31].
The most frequent morphological alteration in TLE is hippocampal sclerosis (HS), this lesion is characterized by extensive neuron loss and formation of pathological networks [33]. The presence of HS with a significant decrease of hippocampal volume correlates with higher rates of FR and lower rates of ripples, which supports the theory that ripples require the integrity of bigger network, whereas FR can generate in very small clusters of pathologically interconnected principal cells [1].

\section{Extra-temporal epilepsies}

Neocortical epilepsies also manifest HFO, and have very different forms of presentation and severity. A study made in patients with intractable partial epilepsy showed FR only in focalized seizures [34]. It has also been found, that regardless of the site of lesion, pediatric patients with symptomatic forms of neocortical epilepsies presented a better outcome when the area of FR was resected, in relation with visible lesions on MRI [35] (Table 2). An interesting proposal for a noninvasive approach in children with absence seizure was the utilization of magneto encephalography, where the activity in the ripple and FR band was localized, primarily in the medial prefrontal cortex [36].

\begin{tabular}{|c|c|c|c|c|c|c|c|}
\hline $\begin{array}{l}\text { Ref. } \\
\text { Number }\end{array}$ & Patients & Type of epilepsy & HFO & $\begin{array}{l}\text { Recording } \\
\text { Technique }\end{array}$ & $\begin{array}{l}\text { Electrode } \\
\text { Number/position }\end{array}$ & $\begin{array}{l}\text { Associated } \\
\text { Technique }\end{array}$ & $\begin{array}{l}\text { Surgical } \\
\text { outcome }\end{array}$ \\
\hline [1] & 9 & TLE & $\mathrm{R}, \mathrm{FR}$ & Depth microelectrode EEG & $14(\mathrm{~A}, \mathrm{H}, \mathrm{EC}, \mathrm{PS}, \mathrm{PH})$ & MRI & NE \\
\hline [28] & 9 & $\begin{array}{l}\text { Symptomatic } \\
\text { Neocortical }\end{array}$ & $R$ & $\begin{array}{l}\text { Subdural } \quad \text { EEG with } \\
\text { macroelectrodes SR } 1000 \mathrm{~Hz}\end{array}$ & $25-120$, variable position & $\begin{array}{l}\text { MRI, Scalp video } \\
\text { EEG, MEG }\end{array}$ & $\begin{array}{l}4 \text { seizure } \\
\text { Free } 60 \% \text { HFO } \\
\text { in RA } \\
5 \text { cases } 36 \% \\
\begin{array}{l}\mathrm{HFO} \text { in } \mathrm{RA}, \\
\text { residual } \\
\text { pathology }\end{array}\end{array}$ \\
\hline [38] & 10 & TLE, Neocortical & $\mathrm{R}, \mathrm{FR}$ & $\begin{array}{l}\text { Cortical and depth electrodes } \\
\text { SR } 2000\end{array}$ & 4-9 (A,H,PH) & EMG, EOG & NE \\
\hline [39] & 4 & TLE, Neocortical & $\mathrm{R}, \mathrm{FR}$ & $\begin{array}{l}\text { MEA, subdural and depth } \\
\text { microelectrodes } \\
\text { SR } 30000 \mathrm{~Hz}\end{array}$ & $\begin{array}{l}96+\text { temporal and frontal } \\
\text { lobes }\end{array}$ & ECoG & NE \\
\hline [40] & 4 & $\begin{array}{l}\text { Epilepsy secondary } \\
\text { to cortical dysplasia }\end{array}$ & $\mathrm{R}, \mathrm{FR}$ & $\begin{array}{l}\text { Stereo EEG, depth multicontact } \\
\text { macroelectrodes } \\
\text { SR } 1024 \mathrm{~Hz}\end{array}$ & $\begin{array}{l}\text { Operculum, prefrontal cortex, } \\
\text { precentral } \\
\text { orbitofrontal cortex }\end{array}$ & MRI & $\begin{array}{l}4 \quad \text { cases } \\
\text { seizure free, } 2 \\
\text { cases } \\
\text { significantly } \\
\text { reduced }\end{array}$ \\
\hline [29] & 13 & $\begin{array}{l}\text { Temporal and extra- } \\
\text { temporal }\end{array}$ & $\mathrm{R}, \mathrm{FR}$ & $\begin{array}{l}\text { Subdural and depth electrodes } \\
\text { SR } 1000 \mathrm{~Hz}\end{array}$ & $2-16$ & $\begin{array}{l}\text { MRI, MEG, sensory } \\
\text { evoked potentials }\end{array}$ & $\begin{array}{l}\text { Resection of } \\
\text { FR } \\
\text { with } \text { correlated } \\
\text { better }\end{array}$ \\
\hline
\end{tabular}




\begin{tabular}{|c|c|c|c|c|c|c|c|}
\hline & & & & & & & $\begin{array}{l}\text { surgical } \\
\text { outcome. }\end{array}$ \\
\hline [37] & 45 & BCECTS, PS & $\mathrm{R}$ & $\begin{array}{l}\text { Scalp sleep EEG } \\
\text { SR } 500 \mathrm{~Hz}\end{array}$ & $10-20$ system & None & $\begin{array}{l}\text { Non } \\
\text { Surgical }\end{array}$ \\
\hline [30] & 44 & $\begin{array}{l}\text { Lesional and } \\
\text { nonlesional }\end{array}$ & $R, F R$ & $\begin{array}{l}\text { Subdura } \\
\text { SR } 2000 \mathrm{Hzl}\end{array}$ & variable & MRI, CT & $\begin{array}{l}\text { Resection of } \\
\text { HFO correlated } \\
\text { with better } \\
\text { surgical } \\
\text { outcome. }\end{array}$ \\
\hline [41] & 32 & $\begin{array}{l}\text { Frontal, parietal, } \\
\text { central, temporal, } \\
\text { occipital }\end{array}$ & $\mathrm{R}$ & $\begin{array}{l}\text { Scalp EEG } \\
\text { SR } 1000 \mathrm{~Hz}\end{array}$ & $10-20$ system +6 & MRI & NE \\
\hline [32] & 22 & $\begin{array}{l}\text { FCD, HS, frontal, } \\
\text { nonlesional }\end{array}$ & $R, F R$ & $\begin{array}{l}\text { Neocortical grid electrodes } \\
\text { SR } 1024 \mathrm{~Hz}\end{array}$ & variable & MRI & $\begin{array}{lr}\text { Resection } & \text { of } \\
\text { FR } & \text { areas } \\
\text { showed } & \text { more } \\
\text { affinity } & \text { whith } \\
\text { seizure } & \\
\text { freedom } & \end{array}$ \\
\hline [42] & 35 & Neocortical & $\mathrm{R}, \mathrm{FR}$ & $\begin{array}{l}\text { Subdural, depth electrodes and } \\
\text { stereo EEG } \\
\text { SR } 2000 \mathrm{~Hz}\end{array}$ & variable & MRI & $\begin{array}{l}\mathrm{FR} \text { only in } \\
\mathrm{SOZ} \text { surgical } \\
\text { outcome NE }\end{array}$ \\
\hline [43] & 12 & TLE, Multifocal & $R, F R$ & $\begin{array}{l}\text { Depth microelectrodes } \\
\text { SR } 2000 \mathrm{~Hz}\end{array}$ & $6-10$ & MRI & Highly variable \\
\hline [44] & 14 & TLE, frontal & R. FR & $\begin{array}{l}\text { ECoG } \\
\text { SR } 2048 \mathrm{~Hz}\end{array}$ & 128 channels & MRI & $\begin{array}{l}9 \text { with FR, } 5 \\
\text { good outcome }\end{array}$ \\
\hline
\end{tabular}

Table 2: Representative studies of the brain topologies where high frequency oscillations can be found and technical specifications of recording.

Abbreviations: A: Amygdala; H: Hippocampus; EC: Entorhinal cortex; PS: Presubiculum, PH: Parahippocampal gyrus, TLE: Temporal Lobe Epilepsy; MRI: Magnetic Resonance Imaging; EEG: Electroencephalography; MEG: Magnetoencephalography; RA: Resection Area; BCECTS: Benign Childhood Epilepsy with CentroTemporal Spikes; PS: Panayiotopoulos Syndrome; ECoG: Electrocorticogram; EOG: Electroculogram; EMG: Electromyography; MEA: Microelectrode Array; FCD: Focal Cortical Dysplasia; HS: Hippocampal sclerosis; CT: Computed tomography; R: Ripples; FR: Fast Ripples; HS: Hippocampal Sclerosis

\section{Conclusion}

In order to associate a high frequency activity to an epileptogenic process, there must be and extensive search of the discrete topology of this activity. In this context temporal structures have been more studied, and as several groups support the identification of ripples within dentate gyrus and FR in any localization, highly correlate with the $\mathrm{SOZ}$ and good surgical outcome when these clusters are removed.

FR in neocortical epilepsies have also proven their value as a biomarker, the preferred technique to obtain the EEG is with a combination of depth and subdural electrodes, and a high sampling rate at $1000 \mathrm{~Hz}$ or above. The recordings have shown that FR highly correlates with SOZ. Even if surgical outcome is mostly positive when FR is resected, the possibility of multifocal epilepsies hinders these percentages when compared with the surgical outcome observed in TLE surgeries from previous works.
FR are increasingly gaining attention due to their potential role as a biomarker; however there are many challenges that must be overcome before its use could become habitual in the clinical practice.

These challenges are, mostly, the difficulty of recording FR noninvasively, as noted before; ripples frequencies are elicited by larger amounts of tissue, and therefore easier to record in scalp EEG [37]. In this study the ripple activity was detected in neocortex. The proposed noninvasive recordings must be compared with the traditional approach in order to accurately determine its specificity and sensibility.

This situation must be considered, particularly in non-surgical types of epilepsy in order to analyze the role of FR as a key in the decision making process regarding the pharmacotherapy of newly diagnosed patients, as well as those considered in remission.

\section{Acknowledgements} LMC.

This review was supported by grant CONACYT-SEP-CB 106179 to

\section{References}

1. Bragin A, Wilson CL, Engel J Jr (2000) Chronic epileptogenesis requires development of a network of pathologically interconnected neuron clusters: a hypothesis. Epilepsia 41: S144-S152.

2. Medina-Ceja L, Morales-Villagrán A, Tapia R (2000) Action of 4aminopyridine on extracellular amino acids in hippocampus and entorhinal cortex: a dual microdialysis and electroencehalographic study in awake rats. Brain Res Bull 53: 255-262. 
3. Rowley HL, Marsden CA, Martin KF (1995) Differential effects of phenytoin and sodium valproate on seizure-induced changes in gammaaminobutyric acid and glutamate release in vivo. Eur J Pharmacol 294: 541-546.

4. Tapia R, Medina-Ceja L, Peña F (1999) On the relationship between extracellular glutamate, hyperexcitation and neurodegeneration, in vivo. Neurochem Int 34: 23-31.

5. Weaver DF, Pohlmann-Eden B (2013) Pharmacoresistant epilepsy: unmet needs in solving the puzzle(s). Epilepsia 54 Suppl 2: 80-85.

6. Dhamija R, Moseley BD, Cascino GD, Wirrell EC (2011) A populationbased study of long-term outcome of epilepsy in childhood with a focal or hemispheric lesion on neuroimaging. Epilepsia 52: 1522-1526.

7. Berg AT, Shinnar S, Levy SR, Testa FM, Smith-Rapaport S, et al. (2001) Early development of intractable epilepsy in children: a prospective study. Neurology 56: 1445-1452.

8. Hauser E, Freilinger M, Seidl R, Groh C (1996) Prognosis of childhood epilepsy in newly referred patients. J Child Neurol 11:201-204.

9. Spencer SS, Berg AT, Vickrey BG, Sperling MR, Bazil CW, et al. (2007) Health-related quality of life over time since resective epilepsy surgery. Ann Neurol 62: 327-334.

10. Warren CP, Hu S, Stead M, Brinkmann BH, Bower MR, et al. (2010) Synchrony in normal and focal epileptic brain: the seizure onset zone is functionally disconnected. J Neurophysiol 104: 3530-3539.

11. Bartolomei F, Cosandier-Rimele D, McGonigal A, Aubert S, Régis J, et al. (2010) From mesial temporal lobe to temporoperisylvian seizures: a quantified study of temporal lobe seizure networks. Epilepsia 51: 2147-2158.

12. Holmes GL (2013) EEG abnormalities as a biomarker for cognitive comorbidities in pharmacoresistant epilepsy. Epilepsia 54 Suppl 2: 60-62.

13. Engel Jr J (2011) Biomarkers in epilepsy: introduction. Biomark Med 5: 536-544.

14. Bragin A, Engel J Jr, Wilson CL, Fried I, Buzsáki G (1999) Highfrequency oscillations in human brain. Hippocampus 9: 137-142.

15. Lee S, Jones SR (2013) Distinguishing mechanisms of gamma frequency oscillations in human current source signals using a computational model of a laminar neocortical network. Front Hum Neurosci 7: 869.

16. Buzsáki G, Horváth Z, Urioste R, Hetke J, Wise K (1992) High-frequency network oscillation in the hippocampus. Science 256: 1025-1027.

17. Yun SH, Mook-Jung I, Jung MW (2002) Variation in effective stimulus patterns for induction of long-term potentiation across different layers of rat entorhinal cortex. J Neurosci 22: RC214.

18. Traub RD, Miles R, Jefferys JGR (1993) Synaptic and intrinsic conductances shape picrotoxin-induced synchronized after-discharges in the guinea-pig hippocampal slice. J Physiol 461: 525-547.

19. Ylinen A, Bragin A, Nádasdy Z, Jandó G, Szabó I, et al. (1995) Sharp wave-associated high-frequency oscillation $(200 \mathrm{~Hz})$ in the intact hippocampus: network and intracellular mechanisms. J Neurosci 15: 30-46.

20. Csicsvari J, Hirase H, Czurkó A, Mamiya A, Buzsáki G (1999) Oscillatory coupling of hippocampal pyramidal cells and interneurons in the behaving Rat. J Neurosci 19: 274-287.

21. Bragin A, Mody I, Engel J Jr (2007) Pathological high frequency oscillations reflect bhypersynchronization of action potentials. Neuron 55: 930-941.

22. Bragin A, Benassi SK, Kheiri F, Engel J Jr (2011) Further evidence that pathologic high-frequency oscillations are bursts of population spikes derived from recordings of identified cells in dentate gyrus. Epilepsia 52: 45-52.

23. Staba RJ (2012) Normal and Pathologic High-Frequency Oscillations: Jasper's Basic mechanisms of the epilepsies. 4th edition, Bethesda (MD): National Center for Biotechnology Information (US).

24. Dzhala VI, Staley KJ (2004) Mechanisms of fast ripples in the hippocampus. J Neurosci 24: 8896-8906.
25. Schmitz D, Schuchmann S, Fisahn A, Draguhn A, Buhl EH, et al. (2001) Axo-axonal coupling. a novel mechanism for ultrafast neuronal communication. Neuron 31: 831-840.

26. Jefferys JG (1995) Nonsynaptic modulation of neuronal activity in the brain: electric currents and extracellular ions. Physiol Rev 75: 689-723.

27. Ogren JA, Wilson CL, Bragin A, Lin JJ, Salamon N, et al. (2009) Threedimensional surface maps link local atrophy and fast ripples in human epileptic hippocampus. Ann Neurol 66: 783-791.

28. Ochi A, Otsubo H, Donner EJ, Elliott I, Iwata R, et al. (2007) Dynamic changes of ictal high-frequency oscillations in neocortical epilepsy: using multiple band frequency analysis. Epilepsia 48: 286-296.

29. Akiyama T, McCoy B, Go CY, Ochi A, Elliott IM, et al. (2011) Focal resection of fast ripples on extraoperative intracranial EEG improves seizure outcome in pediatric epilepsy. Epilepsia 52: 1802-1811.

30. Fujiwara H, Greiner HM, Lee KH, Holland-Bouley KD, Seo JH, et al. (2012) Resection of ictal high-frequency oscillations leads to favorable surgical outcome in pediatric epilepsy. Epilepsia 53: 1607-1617.

31. Bragin A, Wilson CL, Almajano J, Mody I, Engel J Jr (2004) Highfrequency oscillations after status epilepticus: epileptogenesis and seizure genesis. Epilepsia 45: 1017-1023.

32. Kerber K, Dümpelmann M, Schelter B, Le Van P, Korinthenberg R, et al. (2014) Differentiation of specific ripple patterns helps to identify epileptogenic areas for surgical procedures. Clin Neurophysiol 125: 1339-1345.

33. Babb TL, Wilson CL, Isokawa-Akesson M (1987) Firing patterns of human limbic neurons during stereoencephalography (SEEG) and clinical temporal lobe seizures. Electroencephalogr Clin Neurophysiol 66: 467-482.

34. Jirsch JD, Urrestarazu E, LeVan P, Olivier A, Dubeau F, et al. (2006) High-frequency oscillations during human focal seizures. Brain 129: 1593-1608.

35. Wu JY, Sankar R, Lerner JT, Matsumoto JH, Vinters HV, et al. (2010) Removing interictal fast ripples on electrocorticography linked with seizure freedom in children. Neurology 75: 1686-1694.

36. Miao A, Xiang J, Tang L, Ge H, Liu H, et al. (2014) Using ictal highfrequency oscillations $(80-500 \mathrm{~Hz})$ to localize seizure onset zones in childhood absence epilepsy: A MEG study. Neurosci Lett. 566: 21-26

37. Kobayashi K, Yoshinaga H, Toda Y, Inoue T, Oka M, et al. (2011) Highfrequency oscillations in idiopathic partial epilepsy of childhood. Epilepsia 52: 1812-1819.

38. Jacobs J, LeVan P, Chander R, Hall J, Dubeau F, et al. (2008) Interictal high-frequency oscillations $(80-500 \mathrm{~Hz})$ are an indicator of seizure onset areas independent of spikes in the human epileptic brain. Epilepsia 49: 1893-1907.

39. Schevon CA, Trevelyan AJ, Schroeder CE, Goodman RR, McKhann G Jr, et al. (2009) Spatial characterization of interictal high frequency oscillations in epileptic neocortex. Brain 132: 3047-3059.

40. Brázdil M, Halámek J, Jurák P, Daniel P, Kuba R, et al. (2010) Interictal high-frequency oscillations indicate seizure onset zone in patients with focal cortical dysplasia. Epilepsy Res 90: 28-32.

41. Melani F, Zelmann R, Dubeau F, Gotman J (2013) Occurrence of scalpfast oscillations among patients with different spiking rate and their role as epileptogenicity marker. Epilepsy Res 106: 345-356.

42. Wang S, Wang IZ, Bulacio JC, Mosher JC, Gonzalez-Martinez J, et al. (2013) Ripple classification helps to localize the seizure-onset zone in neocortical epilepsy. Epilepsia 54: 370-376.

43. van Diessen E, Hanemaaijer JI, Otte WM, Zelmann R, Jacobs J, et al. (2013) Are high frequency oscillations associated with altered network topology in partial epilepsy? Neuroimage 82: 564-573.

44. van Klink NE, Van't Klooster MA, Zelmann R, Leijten FS, Ferrier CH, et al. (2014) High frequency oscillations in intra-operative electrocorticography before and after epilepsy surgery. Clin Neurophysiol . 